\title{
Hypothesis
}

\section{Spinal shock and 'brain death': Somatic pathophysiological equivalence and implications for the integrative-unity rationale}

\author{
DA Shewmon*,1 \\ ${ }^{1}$ Pediatric Neurology, UCLA Medical School, Los Angeles, California, USA
}

\begin{abstract}
The somatic pathophysiology of high spinal cord injury (SCI) not only is of interest in itself but also sheds light on one of the several rationales proposed for equating 'brain death' (BD) with death, namely that the brain confers integrative unity upon the body, which would otherwise constitute a mere conglomeration of cells and tissues. Insofar as the neuropathology of BD includes infarction down to the foramen magnum, the somatic pathophysiology of BD should resemble that of cervico-medullary junction transection plus vagotomy. The endocrinologic aspects can be made comparable either by focusing on BD patients without diabetes insipidus or by supposing the victim of high SCI to have pre-existing therapeutically compensated diabetes insipidus. The respective literatures on intensive care for BD organ donors and high SCI corroborate that the two conditions are somatically virtually identical. If SCI victims are alive at the level of the 'organism as a whole', then so must be BD patients (the only significant difference being consciousness). Comparison with SCI leads to the conclusion that if $\mathrm{BD}$ is to be equated with death, a more coherent reason must be adduced than that the body as a biological organism is dead.
\end{abstract}

Keywords: brain death; spinal cord injury; spinal shock; integrative functions; somatic integrative unity; organism as a whole

\section{Introduction}

Spinal shock is a transient functional depression of the structurally intact cord below a lesion, following acute spinal cord injury (SCI). It does not occur with slowly progressive lesions but requires a suddenness of cessation of rostral influences. Its pathophysiology remains poorly understood. The hypo- or nonfunction typically lasts 2-6 weeks, followed by recovery of autonomous, disinhibited functions.

The phenomenon is of interest not only in itself and for its effects on SCI victims and their clinical management. It also carries surprising theoretical implications for a clinically quite unrelated entity, namely 'brain death' (BD): specifically, implications for the rationale for equating $\mathrm{BD}$ with death. (Together with Veatch, ${ }^{1}$ I prefer to place 'brain death' in quotation marks on account of its semantic ambiguity. ${ }^{2}$ ) The various proposed rationales can be subdivided into three main categories, corresponding to three fundamentally different concepts of death: (1) sociological (death is loss of conferred membership in

*Correspondence: D Alan Shewmon, Department of Pediatrics, Division of Neurology, UCLA Medical Center, MDCC 22-474, Box 951752, Los Angeles, California, CA 90095-1752, USA society; its legal definition is culturally relative, and most modern societies happen to have chosen to recognize brain-based diagnoses); (2) psychological (death is loss of personhood due to loss of potential for all mental functions, and the brain is the organ of the mind); or (3) biological (death is loss of physiological, anti-entropic unity of an organism, and the brain is the hierarchically highest integrating organ of the body).

It is to this last category of rationale (and to it only) that the phenomenon of spinal shock is conceptually relevant. It is also historically and politically the most important of the three, being what could be called the standard, quasi-official, or 'orthodox' rationale. The idea that BD is death because the brain is the body's central integrator or 'critical organ', destruction of which entails loss of somatic integrative unity (cessation of the 'organism as a whole'), has been endorsed by a variety of influential individuals and virtually every standard-setting group that has ventured to explicitly articulate a rationale..$^{5-12}$ (For all practical purposes relevant to somatic pathophysiology, 'destruction', is taken as equivalent to 'total brain infarction' and 'irreversible nonfunction. ${ }^{6}$ ) (This is not to say that they do not consider consciousness 
important in itself and also a sign of life. It is simply that for them consciousness is not the decisive factor in determining human death. Rather, what is conceptually pivotal is the vital status of the body as a biological organism: if the body is alive, then the person is alive even if permanently unconscious; if the body (including the brain) is dead, then so is the person). (Thought experiments of isolated living brains are best conceived as involving severely mutilated living bodies, of which all that remains is the brain.) Insofar as the 'physiological kernel' of BD is the brain stem, ${ }^{13}$ the same rationale has been advanced also by advocates of brain-stem formulations of death ${ }^{14,15}$ (for a fuller discussion and critique of which, $\mathrm{see}^{2,16}$ ).

A traditionally cited manifestation of the somatic 'dis-integration' of BD is hemodynamic deterioration and loss of homeostasis, intractably spiraling to imminent and irreversible asystole, 6,7,11,13,15,17-19 although such outcome is not universal or intrinsically necessary. ${ }^{20}$ Still, whether BD is conceived as 'total brain infarction', 5 'irreversible cessation of all functions of the entire brain' ${ }^{6}$ or 'permanent functional death of the brainstem' ${ }^{21}$ it clearly eliminates multiple neural centers involved in somatic integration.

A rarely entertained alternative explanation, however, for the somatic pathophysiology of BD is spinal shock from sudden cessation of rostral influences, as first suggested by Ibe back in 1971:

'The clinical picture was in all cases marked by continuous loss of consciousness and persisting respiratory paralysis. The brain function was constantly extinguished. The primary spinal areflexia, on the other hand, as well as the disorders of pulse and blood pressure after overcoming the spinal shock (about $24-36 \mathrm{~h}$ after the accident), showed a clear tendency to recovery, possibly to complete restitution. ${ }^{22}$

The idea was hardly noticed, appearing in an EEG abstract, with the phrase 'spinal shock' mentioned only in passing.

Later Youngner and Bartlett, critiquing the physiological rationale for 'whole-brain death', alluded to certain other somatic similarities between BD and high cervical cord transection:

'a spinal cord transection at the level of the second cervical vertebrae [sic] . . . leads to the immediate and irreversible loss of spontaneous respiration, cardiovascular stability, and temperature controlall of which are integrating functions. ${ }^{23}$

Again the potential significance of the comparison was largely overlooked.

Could it be that high cord transection and $\mathrm{BD}$ are somatically similar with respect not only to these functions but to others as well? The answer is highly relevant to the question of somatic integrative unity in
$\mathrm{BD}$, ie, to the distinction between a sick, disabled organism and a non-organism. Bernat, in his defense of $\mathrm{BD}$ against recent critiques, alludes to the abovementioned similarities with spinal cord dysfunction but dismisses their relevance in the following way:

'Scholars have pointed out correctly that the spinal cord performs a number of integrative functions for the organism, and that it seems arbitrary and contrived for the whole brain proponents to emphasize the brain's role in integration to the exclusion of that of the spinal cord. While it is true that as part of the central nervous system, the spinal cord has an integrating role, it is not a critical role. For example, many patients have lived long lives with minimal support following complete destruction of the spinal cord by injury or disease. Therefore, the integrating functions served by the spinal cord clearly are not necessary for life and therefore, their absence is not necessary (and certainly not sufficient) for death. Permanent cessation of the clinical functions of the entire brain, therefore, remains the best criterion of death. ${ }^{9}$

The logic behind the word 'therefore' in that last sentence is unclear. The point of the critics' comparison is not that cord function is necessary for biological life (understood at the level of the 'organism as a whole'), but rather that, precisely because it isn't, yet $\mathrm{BD}$ and high cord transection have similar somatic effects, then it logically follows that neither is brain function necessary for biological life (equally at the level of the 'organism as a whole'). The key issue is the extent to which the two conditions are really somatically physiologically similar.

The best way to assess this comparison objectively is to consult relevant clinical literature that has neither the comparison in mind nor any philosophical point to make about the nature of $\mathrm{BD}$, ie, texts on the intensive care of BD and high SCI by specialists with extensive experience in the respective conditions.

To forestall potential misunderstanding, let it be reemphasized that the purpose of this comparison is not to advance a claim that BD is clinically indistinguishable from SCI, which would be absurd. Nor is the issue to which the comparison is relevant the clinical criteria for diagnosing a dead brain (the validity of which is taken for granted for purposes of this paper), but rather one particular conceptual rationale (among several) for equating a dead brain with a dead individual: namely the one that claims that a dead brain equates with a dead body. A quite different rationale, promoted by advocates of 'higher brain' formulations, maintains that the reason why $\mathrm{BD}$ is death is that irreversible unconsciousness constitutes a loss of personhood, regardless of the vital status of the body as a biological organism. ${ }^{1,23-28}$ Plainly, for this rationale the role of consciousness is critical and any physiological comparison with SCI is irrelevant. 
Table 1 Somatic pathophysiological parallels between high cervical cord transection and $\mathrm{BD}$

I. Induction phase of neurologic lesion

A. Direct multisystem damage increases early morality rate

B. Indirect systemic complications from transient sympathetic storm

1. Hypertension

2. Subendocardial ischemia and infarcts

3. Neurogenic pulmonary edema

II. Acute phase

A. Irreversible apnea

B. Quadriplegia

C. Spinal shock

1. 'Somatic' system deactivation

(a) Flaccidity

(b) Depressed tendon reflexes and plantar responses

2. Autonomic system deactivation

(a) Sympathetic (thoracolumbar)

(1) Hypotension

(2) Impaired cardiac contractility

(3) Increased venous capacitance

(4) Bradycardia

(5) Cardiac arrhythmias, especially bradyarrhythmias

(6) Cardiovascular instability can be difficult to treat and lead to early arrest

(7) Paralytic ileus

(b) Parasympathetic (sacral) - flaccid bladder

3. Hypothermia and poikilothermia

D. Relatively preserved hypothalamic-anterior pituitary functions

1. Thyroid function - euthyroid sick syndrome

2. Other anterior pituitary functions - variably affected in BD and of little relevance to somatic unity

E. Predisposition to infection

1. Pneumonia, due to immobility and lack of respiratory protective reflexes

2. Urinary tract infections due to bladder dysfunction and urinary retention

3. Sepsis from decubitus ulcers

F. Actuarial survival curves

1. Biphasic: rapid drop-off, followed by relative stabilization

2. Age effect: younger patients have greater survival potential

III. Chronic phase

A. Resolution of spinal shock $2-6$ weeks after injury return of autonomous cord function

1. Development of spasticity, pathological increase of tendon and cutaneous reflexes

2. Recovery of sympathetic tone

(a) Hemodynamic stabilization

(b) Bradycardia and bradyarrhythmias resolve

(c) Gastrointestinal motility returns and enteral feedings can resume

(d) Piloerection and sweating return

3. Recovery of sacral parasympathetic tone automatic bladder function returns

4. Thermoregulation tends to improve, although most patients remain poikilothermic
Table 1 Continued

B. Intercurrent infections precipitate return of spinal shock and hemodyanmic decompensation

C. Autonomic hyperreflexia (dysreflexia)

The interest of the comparison, therefore, has to do with its implications for the conceptual validity of the biological rationale only-and that interest is heightened by the fact that that rationale happens to be the mainstream or quasi-official one almost everywhere. Thus, the ignoring of consciousness in what follows is in no way intended to belittle the obviously exceeding value of intact consciousness and communicative abilities, which SCI patients enjoy and BD patients lack. Subjective consciousness is simply not the main focus of the 'orthodox' rationale, so it is equally beside the point for the present critique of that rationale.

\section{Method}

The contemporary neuroanesthesia and neuro-intensive care literatures relating to high SCI and $\mathrm{BD}$ were compared, focusing on somatic pathophysiology, symptomatology, treatment, and survival. To compare long-term outcomes with continued aggressive treatment, reliance was made on a compilation of some 175 $\mathrm{BD}$ cases with prolonged survival, ${ }^{20}$ extensively documented in two tables available for a small fee through the National Auxiliary Publications Service (NAPS) (document No. 05467), c/o Microfiche Publications, 248 Hempstead Turnpike, West Hempstead, New York 11552. (Remit in advance in U.S. funds only $\$ 17.50$ for photocopies or $\$ 5.00$ for microfiche. There is a $\$ 25.00$ invoicing charge on all orders filled before payment. Outside U.S. and Canada add postage of $\$ 4.50$ for the first 20 pages and $\$ 1.00$ for each ten pages of material thereafter, or $\$ 5.00$ for the first microfiche and $\$ 1.00$ for each fiche thereafter.)

\section{Results}

\section{Similarities}

The extensive somatic parallels between high SCI and $\mathrm{BD}$, according to the literature, are as follows (outline structure summarized in Table 1).

I. Induction phase of neurologic lesion In both conditions, associated multisystem damage is common and could account for somatic deterioration independently of the neurologic nonfunction.

I.A. Direct multisystem damage The primary etiologies of SCI and BD sometimes directly damage non-neural organs as well: for example, massive trauma. ${ }^{29}$ The early mortality rate in SCI is increased with associated injuries compared to pure cord injury. ${ }^{30,31}$ 
Similarly, the rate of early asystole in BD is increased with associated injuries compared to pure brain injury. ${ }^{20}$

I.B. Indirect systemic complications During induction of experimental cervical cord transection, transient hypertension occurs, probably from massive depolarization of sympathetic preganglionic neurons. ${ }^{32}$ In clinical experience this is not usually observed, presumably because it has already resolved by the time medical assistance arrives. ${ }^{32}$ Analogously, during the process of brain herniation, prior to $\mathrm{BD}$, transient hypertension is common, also due to massive sympathetic hyperactivity and release of circulating catecholamines. ${ }^{18,33,34}$

This sympathetic storm can produce subendocardial ischemia or neurogenic pulmonary edema in acute $\mathrm{SCI}^{31,32,35}$ as well as in severe brain injury. ${ }^{18,33,34,36-41}$ The cardiac pathology associated with experimental BD can be prevented by prior sympathectomy and verapamil, confirming the causal role of sympathetic hyperactivity. ${ }^{42}$

II. Acute phase The non-endocrinologic manifestations of the acute phase are nearly identical in high SCI and BD.

II.A. Irreversible apnea is a hallmark of both cord transection above $\mathrm{C} 4^{32,35,43}$ and BD.

II.B. Quadriplegia characterizes both high cord transection, ${ }^{32,43}$ and $\mathrm{BD}$.

II.C. Spinal shock Immediately upon severe SCI, the intact cord below the lesion functionally shuts down through poorly understood mechanisms. This spinal shock typically lasts 2-6 weeks, after which autonomous cord functions gradually return..$^{32,35,44}$ Its intensity increases with the

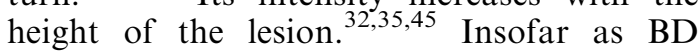
is, from the cord's perspective, a transection at the cervico-medullary junction, one should expect maximal spinal shock in BD. Indeed, in both high cervical transection and BD both 'somatic' and autonomic spinal functions are suppressed as follows. (The semantic tradition distinguishing 'somatic' from 'autonomic' nervous systems is unfortunate, especially for the present purpose, implying that the autonomic system has nothing to do with the body; ironically, the autonomic system is perhaps more important for somatic unity than the 'somatic' system.)

II.C.1. 'Somatic' system deactivation Flaccidity and absence of tendon reflexes and of plantar responses characterize acute $\mathrm{SCI}^{45}$ Although flaccidity is not a diagnostic requirement for $\mathrm{BD}$, it is so common that positive muscle tone should at least raise the question of decorticate or decerebrate rigidity, which would exclude the diagnosis. Likewise, areflexia is so common in $\mathrm{BD}$ that the original Harvard Committee considered it a diagnostic feature (though not absolutely required) along with absent plantar responses. (Subsequent BD criteria emphasized the diagnostic compatibility of preserved tendon reflexes without denying that areflexia is nevertheless more characteristic. $^{6,47,48}$ )

II.C.2. Autonomic system deactivation In spinal shock, autonomic function is as depressed as segmental reflexes. With cervical lesions the entire sympathetic and sacral parasympathetic systems are affected, the sympathetic dysfunction being more deleterious.

II.C.2.a. Symptoms of sympathetic paralysis in both conditions include the following.

(1) Hypotension occurs in $68 \%$ of patients with high $\mathrm{SCI}^{49}$ and can be of life-threatening severity. ${ }^{31,32,35,50}$ Hypotension is also very common in BD. ${ }^{18,20(\text { Table } 1), 33,34,51}$

(2) Impaired cardiac contractility characterizes both $\mathrm{SCI}^{31,32}$ and $\mathrm{BD},{ }^{33}$ as does

(3) Increased venous capacitance. ${ }^{32,33,35}$

(4) In both conditions bradycardia is common and can help in the differential diagnosis of hypotension, suggesting sympathetic paralysis rather than hypovolemic shock (characterized by compensatory tachycardia if the sympathetic system is intact). Hypothermia or subclinical myocardial ischemia can exacerbate bradycardia in either condition. ${ }^{34,52}$

(5) Cardiac arrhythmias occur in 19\% of high SCI, with peak incidence of bradyarrhythmias around day 4. ${ }^{31,32,35,49,53}$ Arrhythmias, especially bradyarrhythmias, are also common in early BD. ${ }^{33,51,54}$

(6) The cardiovascular instability resulting from combined hypotension, impaired myocardial contractility and bradycardia can be difficult to treat and causes significant early mortality in high SCI. ${ }^{53,55}$ An autopsy study of 44 cervical cord injury victims revealed that $30(68 \%)$ died within the first 11 days, mainly of cardiovascular complications. ${ }^{45,56}$ Similarly, intractable cardiovascular instability leads to asys- 
tole in about $10 \%$ of $\mathrm{BD}$ prospective organ donors during the maintenance phase, ${ }^{18,33}$ and '[h]ypotension and/or cardiac arrest occur in approximately two thirds of referred donors'. ${ }^{33}$ Hemodynamic instability renders pharmacologic and fluid management tricky in both conditions, and recommendations are essentially the same. (Some standard vasopressors can have paradoxically deleterious effects in the context of sympathetic paralysis. If a pressor is necessary, dopamine is the drug of choice, but judicious volume expansion without pressors is preferable and often suffices to restore blood pressure to an acceptable range in both $\mathrm{SCI}^{45}$ and $\mathrm{BD} .^{33,34,51}$ The high rate of early cardiac arrest in both conditions is partly iatrogenic, due to inability of the compromised heart to accommodate overly aggressive fluid resuscitation, leading to pulmonary edema and congestive heart failure in less than expert hands. $17,31,33,45,51,53,57$

(7) Paralytic ileus often results from acute autonomic dysfunction and general systemic disturbances in both $\mathrm{SCI}^{32,35,58}$ and $\mathrm{BD},{ }^{20 \text { (Table }} 1$ ) as in serious illnesses in general, requiring parenteral fluids and nutrition until motility returns. ${ }^{53}$

II.C.2.b. Sacral parasympathetic tone is abolished in both conditions, resulting in bladder flaccidity with urinary retention, requiring catheterization. ${ }^{33,53}$

II.C.3. Hypothermia and poikilothermia are common in SCI, due to cutaneous vasodilation (from sympathetic paralysis) causing increased heat loss, plus physical inactivity and inability to shiver (from skeletal muscle paralysis) causing decreased heat generation. ${ }^{31,32,35,50,57}$ For identical reasons, hypothermia and poikilothermia also occur in up to $86 \%$ of BD patients. ${ }^{18,33,34,51}$ Hypothermia exacerbates cardiovascular instability in both conditions, requiring heating lamps and multiple blankets.

Hyperthermia can result from high ambient temperature or high humidity, compounded by absent sympathetic control of sweating, in both $\mathrm{SCI}^{31,32,35,50,57}$ and BD. ${ }^{20(\text { Table }}$ 1) Although in both conditions infection sometimes induces fever, usually it does not. ${ }^{20 \text { (Table } 1), 35}$

II.D. Hypothalamic-anterior pituitary functions, intact in SCI, tend surprisingly to be relatively preserved also in $\mathrm{BD}$, presumably by virtue of the inferior hypophysial artery, which arises extradurally from the internal carotid. ${ }^{18,59-62}$

II.D.1. Thyroid function is frequently altered in $\mathrm{BD}$, but not as hypothalamic hypothyroidism: rather as euthyroid sick syndrome, with relatively normal TSH and $\mathrm{T} 4$ but decreased $\mathrm{T} 3,{ }^{59-63}$ due to decreased peripheral deiodination of $\mathrm{T} 4$ to $\mathrm{T} 3$, perhaps from interleukin- $6^{64,65}$ or free-radical-induced selenium deficiency. (Thus the utility of thyroid replacement therapy for maximizing organ viability remains controversial. ${ }^{18,67}$ Some investigators have reported improved metabolic status and myocardial contractility following triiodothyronine administration in $\mathrm{BD}^{39,68,69}$ or during cardiopulmonary bypass surgery, ${ }^{70,71}$ but this probably represents a direct pharmacologic effect. $^{51,72-74}$ Others have reported no benefit from exogenous T3 in controlled placebo comparisons, ${ }^{75}$ and in one study metabolic acidosis actually worsened. ${ }^{76}$ ) It is a common epiphenomenon of critical illness in general, ${ }^{77,78}$ including SCI. ${ }^{79}$

II.D.2. Other anterior pituitary functions are variably affected in $\mathrm{BD}^{59-62}$ and less relevant for somatic unity. The only indication for even cortisol administration in organ donors is pre-existing adrenal suppression from recent steroids. 8

II.E. Predisposition to infection In both conditions immobility and lack of coughing and sighing promote pneumonia and diminish antibiotic efficacy. ${ }^{20 \text { (Table 1),35,57 Bladder dysfunction }}$ promotes urinary tract infection, ${ }^{20(\text { Table } 1), 32}$ and immobility predisposes to decubitus ulcers with local infection and risk of sepsis. Preventive nursing care is identical for both conditions.

\section{II.F. Actuarial survival curves}

II.F.1. High cervical quadriplegia has a biphasic survival curve, with rapid drop-off in the first three months (especially the first). In one study 3-month survival was only $43 \%{ }^{80}$ The subsequent chronic phase has a relatively low death rate. ${ }^{80-82}$ Survival curves for BD treated equally aggressively also feature a rapid drop-off over the first several months (especially the first), followed by a chronic phase of relative stabilization. ${ }^{20}$

II.F.2. Age is a significant determinant of survival rate. Following SCI the proportion alive at a given time after injury decreases significantly with advancing

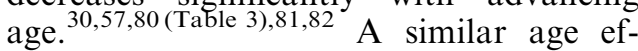


fect characterizes survival potential in BD. ${ }^{20}$

III. Chronic phase

III.A. Resolution of spinal shock Beginning 2-6 weeks after SCI, autonomous cord function gradually returns. In the few $\mathrm{BD}$ patients maintained through the acute phase, spinalshock symptomatology also gradually resolves around the same time frame, producing relative somatic stabilization.

III.A.1. Development of spasticity Following SCI the first clinical manifestation of recovery from spinal shock is return of tendon and cutaneous reflexes, which soon become hyperactive as flaccid tone becomes spastic. ${ }^{32,35,44}$ Triple flexion (hips, knees, ankles) and other withdrawal reflexes appear in response to noxious stimuli. ${ }^{32,44,45}$ In prolonged BD, tone and reflexes likewise become pathologically increased (barring intrinsic damage to the cord). ${ }^{20}$ (Unfortunately, the available information regarding the time course of these changes is too scanty for comparison with SCI.)

III.A.2. Sympathetic tone returns in parallel with skeletal muscle tone and is perhaps the most important systemic aspect of recovery from spinal shock.

III.A.2.a During the weeks following SCI, hemodynamic status stabilizes: vasopressors can be weaned, the heart better accommodates fluctuations in intravascular volume, and fluid management simplifies. ${ }^{31,35,43}$ Exactly the same occurs in chronic $\mathrm{BD}$; prior to 4 weeks the most frequent terminal event is spontaneous asystole, whereas after 4 weeks it is treatment withdrawal. ${ }^{20}$

III.A.2.b In SCI bradycardia and bradyarrhythmias completely resolve by $2-6$ weeks. ${ }^{49,55}$ Similarly, in prolonged BD cardiac rhythm also stabilizes. 20 (Table 1)

III.A.2.c In SCI gastrointestinal motility returns and enteral feedings can resume. ${ }^{35,57}$ The same is true in some prolonged BD cases (through the intrinsic neurenteric plexus and intraspinal autonomic integration), ${ }^{20(\text { Table } 1)}$ although lack of swallowing requires providing enteral feedings by tube, in contrast to SCI.

III.A.2.d In SCI piloerection and sweating gradually return. ${ }^{32}$ Parallel data for chronic BD are lacking in the literature, although in one patient whom the author personally examined

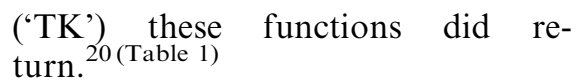

III.A.3 Recovery of sacral parasympathetic tone In SCI automatic bladder function gradually returns. ${ }^{32}$ Urinary retention and associated urinary tract infections become less problematic as bladder spasticity causes smaller capacity and frequent spontaneous voidings. Again, parallel data are lacking for prolonged BD, although patient 'TK' did develop such bladder function, with spontaneous micturition about every $2 \mathrm{~h} .^{20(\text { Table } 1)}$

III.A.4 In both SCI and BD thermoregulation improves, although most patients remain poikilothermic to some degree; hyperthermia can occur in the absence of infection, possibly from spastic hypertonia or autonomic dysreflexia (see below). ${ }^{20 \text { (Table 1),57 }}$

III.B. In both conditions intercurrent infections can precipitate recurrence of spinal shock with dramatic hemodynamic decompensation. The symptoms dissipate upon resolution of the infection. ${ }^{20}$ (Table 1),44

III.C. Autonomic hyperreflexia (dysreflexia) develops in $65-85 \%$ of SCI cases, with sudden episodes of severe hypertension triggered by noxious or visceral stimuli (eg, defecation, full bladder, tracheal suctioning). $31,32,35,45,50$ Manifestations include profuse flushing and diaphoresis of head and neck, nasal congestion, headache and chest pain. Pathogenesis probably involves denervation hypersensitivity of peripheral adrenergic receptors. ${ }^{45}$

Reflex hypertensive responses to surgical incision in unanesthetized BD organ donors are similar (apart from heart rate-see below) yet occur much earlier than the several weeks typically required for development of autonimic dysreflexia following SCI. ${ }^{18,83-89}$ The timing may not represent a real point of difference, however. Little is known about the hemodyanmic response to unanesthetized surgery in acute SCI, since anesthesia is typically employed. Perhaps splitting the entire thorax and abdomen is a stimulus powerful enough to overcome any spinal shock.

Less is known about autonomic dysreflexia in chronic BD, but some case reports do mention episodes of hypertension after a latency of several

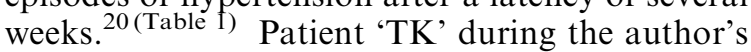
examination developed transient blotchy erythema of the face, neck and shoulders in response to noxious stimuli such as pinching or ice-water trickling down the neck. Nurses have documented that such reaction is characteristically associated with a transient rise in blood pressure and heart rate. 


\section{Differences}

The extensiveness of somatic parallels between SCI and BD contrasts markedly with the relative paucity and unimportance of the differences, as follows (outline structure summarized in Table 2).

I. Hypothalamic-posterior pituitary function is intact in SCI and variable in BD. Diabetes insipidus occurs in $38-87 \%$ of BD patients. ${ }^{18,33,59-62,90}$ The inconsistency presumably stems from vicissitudes of vascular supply from the same extradural collaterals responsible for preserving anterior pituitary functions (see above). If inadequately treated, the ensuing hypovolemia and electrolyte imbalance will exacerbate the already tenuous cardiovascular status. Diabetes insipidus can appear after a brief latency following $\mathrm{BD}$, and in some chronic cases (eg, 'TK') it can also gradually resolve. ${ }^{20 \text { (Table } 1)}$

II. Vagus nerve functions are intact in SCI and absent in BD.

II.A. Efferent functions

II.A.1. Bradycardia In BD loss of both sympathetic and parasympathetic functions leaves the heart's rate determined solely by its intrinsic pacemaker, which is slower than normal and lacks spontaneous variability. ${ }^{91,92}$ The bradycardia of high SCI is even more profound due to unopposed parasympathetic tone, ${ }^{31,32,35,55}$ and severe reflex bradycardia can be precipitated by vagal stimulation such as intubation, oropharyngeal suctioning, ocular pressure, or a sigh. ${ }^{35}$ Such disadvantageous reactions do not occur in BD. Atropine can treat and prevent severe bradycardia in SCI ${ }^{45}$ but has no chronotropic effect in BD because vagal function is already absent. ${ }^{33}$

Table 2 Somatic pathophysiological differences between high cervical cord transection and BD

I. Hypothalamic-posterior pituitary function (diabetes insipidus in $38-87 \%$ of $\mathrm{BD}$, absent in $\mathrm{SCI}$ )

II. Vagus nerve functions (intact in SCI, absent in BD)

A. Efferent functions

1. Bradycardia (more severe in SCI due to unopposed vagal tone; a hemodynamic disadvantage compared with BD)

2. Recovery of gastrointestinal motility following spinal shock seems less common in BD than in SCI

B. Afferent function (intact in SCI, absent in BD) irrelevant if BD involves diabetes insipidus

III. Glossopharyngeal nerve function (intact in SCI, absent in BD) - irrelevant if BD involves diabetes insipidus

IV. Associated systemic complications - disseminated intravascular coagulation in $25-65 \%$ of $\mathrm{BD}$, much less in SCI
The bradycardia associated with autonomic hyperreflexia in chronic SCI is vagally mediated. ${ }^{32,35,45,50}$ By contrast, the hypertension upon unanesthetized organ retrieval in $\mathrm{BD}$ (or upon somatic irritation in chronic BD) is associated with tachycardia, presumably mediated by unopposed spinal sympathetic reflexes, including adrenally released circulating catecholamines. ${ }^{18,83-89}$

II.A.2. Recovery of gastrointestinal motility following spinal shock may occur less often in BD than in SCI, perhaps because of the permanent vagal suppression in BD.

II.B. Afferent function The vagus nerve transmits signals from the baroreceptors of the cardiac atria and aortic arch to the nucleus of the tractus solitarius, which participates in regulation of blood pressure and volume through vagal efferent adjustment of heart rate, various bulbospinal pathways and hypothalamic modulation of sympathetic tone and release of antidiuretic hormone. ${ }^{93-95}$ Since rostral control of sympathetic function is abolished in both SCI and BD, and since posterior pituitary function is variably affected in BD, the only meaningful comparison of vagal afferent function between the two conditions involves the subset of $\mathrm{BD}$ without diabetes insipidus. In SCI the atrial and aortic baroreceptors participate through vagal afferents in modulation of vagal efferent tone and antidiuretic hormone secretion, ${ }^{32,45}$ whereas in BD without diabetes insipidus they do not.

III. Glossopharyngeal nerve function is intact in SCI and absent in BD. Together with vagal afferents, a branch of the ninth cranial nerve to the carotid body conveys additional baroreceptor information, all processed together and ultimately influencing homeostasis as just described. ${ }^{93}$ The somatic differences between SCI and BD attributable to glossopharyngeal function are therefore the same as those attributable to vagal afferents, are relatively minor, and are nonexistent in the context of diabetes insipidus.

IV. Associated systemic complications Disseminated intravascular coagulation complicates $25-65 \%$ of $\mathrm{BD}$ organ donors. ${ }^{18,51}$ It is not described in the spinal cord literature, presumably because much less tissue thromboplastin is released by SCI than by massive brain injury.

These, then, are the somatic differences. Note that other cranial nerve functions and especially consciousness, though preserved in SCI and absent in BD, are not listed, because important as they are for the patient, they are unrelated 
to the focus of the comparison, namely somatic pathophysiology insofar as it is relevant to the question whether the body in either condition is a sick organism or a mere collection of organs.

\section{Discussion}

The similarity of effects of SCI and BD on the body is surprising at first sight and fascinating in itself, but its relevance to one of the several rationales advanced to explain why BD should be equated with death elevates the comparison from a mere physiological curiosity to a conceptually important observation.

According to the mainstream, 'orthodox' rationale, the purported loss of somatic integrative unity in $\mathrm{BD}$ is attributable to destruction of the many brain-stem and hypothalamic integrative centers. ${ }^{5-8,11,12,15}$ But is it their destruction per se or rather the body's nonreception of their influence that most immediately affects somatic integration? Surely the latter, because it is more proximate to the phenomenon of interest, it is the means through which the former exerts its effect, and it can also be brought about by other possible causes such as mere disconnection from cephalic structures. That the impact on somatic physiology of nonreception of rostral influence should be indifferent to the reason for the nonreception implies that body A with a destroyed brain and body B with a disconnected brain (eg, due to high SCI) should have the same vital status. Logical consistency demands that if we assert that A is dead as a biological organism, we must be prepared to say the same of B; but if we insist that B is clearly alive as a biological organism (and not merely because it is conscious), then we must be willing to admit the same of $\mathrm{A}$.

\section{Somatic equivalence in theory}

The anatomical pathways through which somatically integrative information is transferred between body and brain are relatively few.

In the afferent direction the routes are threefold:

- spinal cord

- glossopharyngeal and vagus nerves (from the atrial, aortic and carotid baroreceptors), and

- arterial blood flow to the hypothalamus (especially to supraoptic and paraventricular nuclei).

In the efferent direction the routes are likewise threefold:

- spinal cord,

- vagus nerve, and

- pituitary.

The other ten cranial nerves terminate in the head or neck and are irrelevant to somatic integration.
Also note that the second and third afferent pathways are relevant only in contexts where the corresponding efferent limbs are intact. Blood flow to and from the brain in general is conceivably an additional pathway, though not for all practical purposes. Certainly extra-hypothalamic brain has receptors for various hormones and circulating chemicals, but those even remotely relevant to somatic integrative unity involve the hypothalamicpituitary axis. The brain is not known to be a secretory organ (apart from the portal system of the adenohypophysis). Similarly, the production, circulation, and venous absorption of cerebrospinal fluid could be another theoretically conceivable route for brain-body chemical interaction, but there is no evidence that such exchange serves any somatically integrating role.

Plainly disruption of any one of the significant pathways of encephalo-somatic communication does not destroy the unity of the 'organism as a whole'. Every endocrinology clinic has patients with diabetes insipidus or even panhypopituitarism who live perfectly normal lives on replacement therapy. Every major rehabilitation center cares for ventilatordependent patients with high cervical quadriplegia. Sometimes for therapeutic reasons the vagus nerve is ablated surgically or pharmacologically.

What about elimination of two of these three routes? For example, suppose that a high cervical quadriplegic were given atropine to treat bradycardia. The somatic physiology of such a patient would be virtually identical to that of a BD patient without diabetes insipidus (the only difference being preserved carotid-body modulation of antidiuretic hormone in the SCI patient).

To complete the analogy, suppose that the atropinized SCI victim was an endocrinology patient with chronic panhypopituitarism, stable on replacement therapy. The somatic physiology relevant to integrative unity is now absolutely identical to that of total brain infarction. The only difference lies in consciousness and those cranial nerves restricted to head and neck. Is such a body an implacably disintegrating 'collection of organs', or a live 'organism as a whole' that happens to be severely disabled and dependent on medical technology? If the former, then we would have the bizarre anomaly of a 'conscious corpse'; if the latter, then the BD body must equally be an 'organism as a whole' despite its severe disability and technological dependence (its unconsciousness being an additional disability, but not one that per se settles the question: is this an unconscious organism or a non-organism?).

From the body's perspective, BD and atropinized high cord transection are virtually indistinguishable (comparing SCI with the subset of BD without diabetes insipidus, or 'total' BD with the subset of SCI with pharmacologically controlled diabetes insipidus), because the caudal margin of total brain 
infarction is in fact a cervico-medullary junction infarction. Thus, regardless how one might choose to define operationally terms such as 'integrative unity' or 'organism as a whole', if they are defined carefully enough to apply properly to any ventilator-dependent quadriplegic with diabetes insipidus, then ipso facto they will apply as well to any BD patient. ${ }^{96}$

Not only is this conclusion inescapable on theoretical grounds; it is fully ratified in clinical experience.

\section{Somatic equivalence in practice}

The literatures on intensive care of acute SCI and BD are so similar that they can almost be mutually transformed one into the other merely by interchanging the terms 'SCI' and 'BD'. Yet this curious fact seems to have passed largely unnoticed, even by authors of respective chapters in the same book (eg, Kofke et al. ${ }^{35}$ and MacKenzie and Geisler ${ }^{45}$ on the one hand, and Lew and Grenvik ${ }^{18}$ on the other).

Induction phase During the process of brain herniation or spinal cord infarction, but prior to BD or complete cord transection, secondary cardiopulmonary pathology (subendocardial microinfarcts, neurogenic pulmonary edema) due to massive sympathetic discharge is common and contributes substantially to the acute hemodynamic instability and early mortality in both BD and SCI. In some cases multiple nonneural organs are also damaged directly by whatever primary etiology damaged the brain or cord.

The time course of subsequent relative stabilization, although attributable largely to recovery from spinal shock, also corresponds to resolution and healing of such multisystem complications. That young patients have much greater potential for survival in both conditions also reinforces the idea that the tendency to early demise is attributable more to somatic than to neurologic factors.

It is therefore fallacious to attribute the increased incidence of early arrhythmias and cardiovascular collapse in BD to the absence of brain function per se. (It is also inconsistent, if a parallel attribution is not made for SCI). Rather, the early systemic instabilities are more likely attributable to systemic pathology, antedating the $B D$ as suggested also by Novitzky. ${ }^{39}$ If the brain or cord become infarcted in a way that does not overactivate the sympathetic system, cardiopulmonary complications should be much less of a problem $\left(\mathrm{cf}^{42}\right)$.

Spinal shock The comparison of SCI and BD literatures reveals that every described manifestation of spinal shock also occurs in $\mathrm{BD}$, and conversely, every non-endocrinologic systemic dysfunction characteristic of BD (excluding associated multisystem injury) is explainable in terms of spinal shock. Nevertheless, despite the similarities of somatic symptomatology and the theoretical grounds for equating the somatic pathophysiology of $\mathrm{BD}$ with that of cervico-medullary junction transection, a marked explanatory asymmetry has prevailed.

The SCI literature attributes a particular set of signs and symptoms to functional suppression of the structurally intact spinal cord below the lesion, below the foramen magnum, and calls it 'spinal shock'. By contrast, the BD literature attributes the same set of signs and symptoms directly to destruction of brainstem vegetative control centers above the foramen magnum and calls it 'loss of somatic integrative unity'.

For example, depressed sympathetic tone in SCI is usually attributed to deactivation of second-order sympathetic neurons in the intermediolateral cell column, but in BD it is typically attributed to destruction of first-order sympathetic neurons in the hypothalamus and their axons in passage through the medulla $\left(\mathrm{eg},{ }^{97}\right)$. But since BD includes cervicomedullary junction infarction, in the context of which the rostral integrity of the sympathetic system is physiologically irrelevant, the most parsimonious explanation of impaired sympathetic tone in BD is spinal shock, just as in SCI. As another example, it is illogical to attribute hypothermia in BD to destruction of hypothalamic thermoregulatory centers (as does $\operatorname{Gert}^{10}$ ), when the same hypothermia would result from the caudal end of the brain pathology alone (ie, cervico-medullary junction infarction) even if the hypothalamus and medulla were intact, as in SCI.

The same could be said about every other nonendocrinologic somatic dysfunction in BD. This explanatory asymmetry is probably motivated by an a priori conviction that $\mathrm{BD}$ ought to be equated with organismal death and SCI not; regardless, it is a logical double standard without physiological basis.

Moreover, because unopposed parasympathetic tone is more disadvantageous hemodynamically than absence of both sympathetic and parasympathetic tone, one could argue that, precisely because vagal function is intact in SCI and often needs to be pharmacologically suppressed, SCI bodies are ironically even less integrated than $B D$ bodies (at least those without diabetes insipidus). Therefore, if despite this disadvantage SCI patients still possess enough integrative unity to quality as living 'organisms as a whole', all the more do BD patients.

The similarity of survival curves of the two conditions also argues that high SCI is every bit as somatically 'dis-integrating' as BD during the acute phase, yet no one concludes therefore that the bodies of SCI patients are ipso facto 'dead' or are mere collections of organs without unity at the level of the 'organism as a whole'. Conversely, the somatic instability in $\mathrm{BD}$ is potentially every bit as transient as in SCI. If it looks like spinal shock, acts like spinal shock, resolves like spinal shock - why not call it spinal shock? 
Whether the somatic symptomatology of BD is best understood as manifesting 'loss of integrative unity' or 'spinal shock' is answerable through considering the constellation and temporal evolution of clinical signs. The comparison is greatly obscured by the fact that BD patients are typically not supported for the 2-6 weeks necessary to manifest the resolution characteristic of spinal shock. But the case reports of BD patients who have been so maintained ${ }^{20}$ indicate that the respective somatic symptomatologies of $\mathrm{BD}$ and SCI do in fact closely parallel one another. The parallel is not only qualitative (signs, symptoms) and quantitative (severity, high rate of early asystole) but also temporal (gradual return of autonomous cord function and somatic stabilization)-unless, of course, the BD patient also sustained diffuse spinal cord infarction or injury, a common yet under-appreciated association, especially if the etiology is anoxicischemic.

Endocrinologic differences Apart from consciousness and the strictly cephalic cranial nerves, the only significant difference between high SCI and BD is hypothalamic-pituitary function. But hypothalamic dysfunction or nonfunction has never been a diagnostic requirement for $\mathrm{BD}$ : neither according to the original Harvard Committee, ${ }^{46}$ nor the President's Commission, ${ }^{6}$ nor the British Conference of Medical Royal Colleges, ${ }^{14}$ nor the Swedish Committee, ${ }^{5}$ nor the Task Force for the Determination of Brain Death in Children, ${ }^{98}$ nor the myriad other proposers of diagnostic criteria. ${ }^{99}$ Diabetes insipidus is absent in $13-62 \%$ of $\mathrm{BD}$ potential organ donors. ${ }^{18,33}$ Significantly, preservation of such somatically integrative hypothalamic function is declared explicitly compatible with the diagnosis of $\mathrm{BD}$ according to the most recent practice parameter of the American Academy of Neurology, ${ }^{47}$ even though it contradicts the very definition of 'whole-brain death'. ${ }^{100-102}$ For this subgroup of $\mathrm{BD}$, the somatic physiologic distinction from atropinized high spinal cord transection is virtually nonexistent.

\section{Conclusion}

In summary, if the loss of brain-regulation of the body in the one context (SCI) is insufficient to constitute cessation of the 'organism as a whole', then the same loss of brain-regulation must be equally insufficient in the other context (BD). To be sure, total brain destruction is a fatal lesion, but 'fatal' in the sense of a strong tendency to bodily death (which can be opposed by medical intervention) rather than per se equalling bodily death. The brain cannot be construed with physiological rigor as the body's 'central integrator', in the sense of conferring unity top-down on what would otherwise be a mere collectivity of organs. Neither is any other organ 'the central integrator'. A living body possesses not an integrator but integration, a holistic property deriving from the mutual interaction among all the parts. ${ }^{96}$

If $\mathrm{BD}$ is to be coherently equated with death, 'death' must therefore be understood in a nonbiological sense, as proponents of 'higher-brain' or consciousness formulations have advocated. ${ }^{1,23-28}$ Whether society will want to adopt such a concept of death-which amounts to a notion of the human person as not only conceptually distinct, but actually dissociable, from a living human body-remains to be seen. That debate exceeds the present scope. What is clear from a somatic pathophysiological comparison with SCI is that the mainstream assertion that BD represents biological death of the human 'organism as a whole' is physiologically untenable.

\section{References}

1 Veatch RM. The impending collapse of the whole-brain definition of death [published erratum appears in Hastings Cent Rep 1993; 23(6):4]. Hastings Cent Rep 1993; 23(4): 18 - 24.

2 Shewmon DA. 'Brain death': a valid theme with invalid variations, blurred by semantic ambiguity. In: White RJ, Angstwurm H, Carrasco de Paula I (eds). Working Group on the Determination of Brain Death and its Relationship to Human Death. 10-14 December, 1989. (Scripta Varia 83). Pontifical Academy of Sciences, Vatican City 1992, pp 23-51.

3 Byrne PA, O'Reilly S, Quay PM. Brain death - an opposing viewpoint. JAMA 1979; 242: 1985-1990.

4 Byrne PA, O'Reilly S, Quay PM, Salsich PW Jr. Brain death the patient, the physician, and society. Gonzaga Law Rev 1982/ 83; 18: $429-516$.

5 Swedish Committee on Defining Death. The concept of death. Summary. Swedish Ministry of Health and Social Affairs: Stockholm 1984.

6 President's Commission for the Study of Ethical Problems in Medicine and Biomedical and Behavioral Research. Defining Death: Medical, Legal, and Ethical Issues in the Determination of Death. U.S. Government Printing Office: Washington, DC 1981.

7 Bernat JL. The definition, criterion, and statute of death. Semin Neurol 1984; 4: 45-51.

8 Bernat JL. Ethical Issues in Neurology. Butterworth-Heinemann: Boston 1994, pp 113-143.

9 Bernat JL. A defense of the whole-brain concept of death. Hastings Cent Rep 1998; 28(2): 14-23.

10 Gert B. A complete definition of death. In: Machado C (ed). Brain Death. Proceedings of the Second International Conference on Brain Death. Havana, Cuba, February 27-March 1, 1996. Elsevier: Amsterdam 1995, pp 23-30.

11 Korein J. The problem of brain death: development and history. Ann NY Acad Sci 1978; 315: 19-38.

12 White RJ, Angstwurm H, Carrasco de Paula I. Final considerations formulated by the scientific participants. In: White RJ, Angstwurm H, Carrasco de Paula I (eds). Working Group on the Determination of Brain Death and its Relationship to Human Death. 10-14 December 1989. (Scripta Varia 83), Pontifical Academy of Sciences: Vatican City. 1992, pp 81-82.

13 Pallis C. Whole-brain death reconsidered-physiological facts and philosopy. J Med Ethics 1983; 9: $32-37$.

14 Conference of Medical Royal Colleges and their Faculties in the United Kingdom. Diagnosis of death. Br Med J 1979; 1: 3320. [also Lancet 1979; 1: $261-262$ ].

15 Lamb D. Death, Brain Death and Ethics. State University of New York Press: Albany, NY 1985.

16 Shewmon DA. 'Brain-stem death', 'brain death' and death: a critical re-evaluation of the purported evidence. Issues Law Med 1998; 14: $125-145$. 
17 Guerriero WG. Organ transplantation. In: Narayan RK, Wilberger Jr JE, Povlishock JT (eds). Neurotrauma. McGrawHill: New York 1996, pp 835-840.

18 Lew TWK, Grenvik A. Brain death, vegetative state, donor management, and cessation of therapy. In: Albin MS (ed) Textbook of Neuroanesthesia with Neurosurgical and Neuroscience Perspectives. McGraw-Hill: New York 1997, pp $1361-1381$.

19 Pallis C, Harley DH. ABC of Brainstem Death. BMJ Publishing Group: London 1996.

20 Shewmon DA. Chronic 'brain death': meta-analysis and conceptual consequences. Neurology 1998; 51: $1538-1545$.

21 Conference of Medical Royal Colleges and their Faculties in the United Kingdom. Diagnosis of brain death. Br Med J 1976; 2: 1187 - 1188 [also Lancet 1976; 2: 1069-1070].

22 Ibe K. Clinical and pathophysiological aspects of the intravital brain death [abstract]. Electroencephalogr Clin Neurophysiol 1971; 30: 272.

23 Youngner SJ, Bartlett ET. Human death and high technology: the failure of the whole-brain formulations. Ann Intern Med 1983; 99: $252-258$

24 Gervais KG. Redefining Death. Yale University Press: New Haven 1986.

25 Green MB, Wikler D. Brain death and personal identity. In: Cohen M, Nagel T, Scanlon T (eds). Medicine and Moral Philosophy. A Philosophy and Public Affairs Reader. Princeton University Press: Princeton, NJ 1982, pp 49-77.

26 Lizza JP. Persons and death: What's metaphysically wrong with our current statutory definition of death? J Med Philos 1993; 18: $351-374$

27 Machado C. A new definition of death based on the basic mechanisms of consciousness generation in human beings. In: Machado C (ed). Brain Death. Proceedings of the Second International Conference on Brain Death. Havana, Cuba, February 27-March 1, 1996. Elsevier: Amsterdam 1995, pp $57-66$.

28 Zaner RM. Death: Beyond Whole-Brain Criteria. Kluwer Academic Publishers: Dordrecht/Boston 1988

29 Matjasko MJ. Multisystem sequelae of severe head injury. In: Cottrell JE, Smith DS (eds). Anesthesia and Neurosurgery. 3rd edn. Mosby: St. Louis 1994, pp 685-712.

30 Geisler WO, Jousse AT. Life expectancy following traumatic spinal cord injury. In: Frankel HL (ed). Spinal Cord Trauma. Elsevier Science Publishers: Amsterdam 1992, 499-513.

31 Teeple E, Heres EK. Anesthesia management of spinal trauma. In: Narayan RK, Wilberger Jr JE, Povlishock JT (eds) Neurotrauma. McGraw-Hill: New York 1996, pp 1167-1177.

32 Albin MS. Spinal cord injury. In: Cottrell JE, Smith DS (eds). Anesthesia and Neurosurgery. 3rd edn. Mosby: St. Louis 1994 pp $713-743$.

33 Darby JM, Stein K, Grenvik A, Stuart SA. Approach to management of the heartbeating 'brain dead' organ donor. JAMA 1989; 261: 2222 - 2228 .

34 Field DR et al. Maternal brain death during pregnancy: medical and ethical issues. JAMA 1988; 260: 816-822.

35 Kofke WA, Yonas H, Wechsler L. Neurologic intensive care. In: Albin MS (ed). Textbook of Neuroanesthesia with Neurosurgical and Neuroscience Perspectives. McGraw-Hill: New York 1997, pp $1247-1347$.

36 Antonini $\mathrm{C}$ et al. Morte cerebrale e sopravvivenza fetale prolungata. [Brain death and prolonged fetal survival] Minerva Anestesiol 1992; 58: $1247-1252$.

37 Novitzky D et al. Pathophysiology of pulmonary edema following experimental brain death in the chacma baboon Ann Thorac Surg 1987; 43: $288-294$

38 Novitzky D, Rose AG, Cooper DK. Injury of myocardial conduction tissue and coronary artery smooth muscle following brain death in the baboon. Transplantation 1988; 45: 964-966.

39 Novitzky D. Heart transplantation, euthyroid sick syndrome, and triiodothryonine replacement. J Heart Lung Transplant 1992; 11(4 pt2): S196-S198.
40 Samuels MA. Cardiopulmonary aspects of acute neurologic diseases. In: Ropper AH (ed). Neurological and Neurosurgical Intensive Care. 3rd edn. Raven Press: New York 1993; pp $103-$ 119.

41 Yoshida K-I, Ogura Y, Wakasugi C. Myocardial lesions induced after trauma and treatment. Forensic Sci Int 1992; 54: $181-189$.

42 Novitzky D et al. Prevention of myocardial injury during brain death by total cardiac sympathectomy in the Chacma baboon. Ann Thorac Surg 1986; 41: 520-524.

43 Tator $\mathrm{CH}$ Classification of spinal cord injury based on neurological presentation. In: Narayan RK, Wilberger Jr JE, Povlishock JT (eds). Neurotrauma. McGraw-Hill: New York 1996, pp 1059-1073.

44 Eidelberg E. Consequences of spinal cord lesions upon motor function, with special reference to locomotor activity. Prog Neurobiol 1981; 17: 185-202.

45 MacKenzie CF, Geisler FH. Management of acute cervical spinal cord injury. In: Albin MS (ed). Textbook of Neuroanesthesia with Neurosurgical and Neuroscience Perspectives. McGraw-Hill: New York 1997, pp 1083-1136.

46 Beecher HK et al. A defintiion of irreversible coma. Report of the Ad Hoc Committee of the Harvard Medical School to examine the Definition of Brain Death. JAMA 1968; 205: 337-340.

47 American Academy of Neurology - Quality Standards Subcommittee. Practice parameters for determining brain death in adults (Summary statement). Neurology 1995; 45: 1012 - 1014.

48 Wijdicks EF. Determining brain death in adults. Neurology 1995; 45: $1003-1011$.

49 Lehman KG, Lane JG, Piepmeier JM, Batsford WP Cardiovascular abnormalities accompanying acute spinal cord injury in humans: incidence, time course and severity. J Am Coll Cardiol 1987; 10: 46-52.

50 Stoelting RK, Dierdorf SF, McCammon RL. Anesthesia and Co-Existing Disease. Churchill Livingstone: New York 1988, pp $327-328$.

51 Robertson KM, Cook DR. Perioperative management of the multiorgan donor. Anesth Analg 1990; 70: 546-556.

52 Drory Y, Ouaknine G, Kosary IZ, Kellermann JJ. Electrocardiographic findings in brain death; description and presumed mechanism. Chest 1975; 67: 425-432.

53 Rodts Jr GE, Haid Jr RW. Intensive care management of spinal cord injury. In: Narayan RK, Wilberger Jr JE, Povlishock JT (eds). Neurotrauma. McGraw-Hill: New York 1996; pp 1201 1212 .

54 Logigian EL, Ropper AH. Terminal electrocardiographic changes in brain-dead patients. Neurology 1985; 35: 915-918.

55 Winslow EBJ, Lesch M, Talano JV, Meyer Jr PR. Spinal cord injuries associated with cardiopulmonary complications. Spine 1986; 11: 809-812.

56 Wolman L. The disturbance of circulation in traumatic paraplegia in acute and late stages: a pathological study. Paraplegia 1965; 2: $213-226$

57 Cahill DW, Rechtine GR. The acute complications of spinal cord injury. In: Narayan RK, Wilberger Jr JE, Povlishock JT (eds). Neurotrauma. McGraw-Hill: New York 1996, pp 12291236 .

58 Frost FS. Gastrointestinal dysfunction in spinal cord injury. In: Yarkony GM (ed). Spinal Cord Injury. Medical Management and Rehabilitation. Aspen Publishers: Gaithersburg, MD 1994, pp 27-39.

59 Arita $\mathrm{K}$ et al. The function of the hypothalamo-pituitary axis in brain dead patients. Acta Neurochir (Wien) 1993; 123: 64-75.

60 Gramm H-J et al. Acute endocrine failure after brain death? Transplantation 1992; 54: $851-857$.

61 Howlett TA et al. Anterior and posterior pituitary function in brain-stem-dead donors. A possible role for hormonal replacement therapy. Transplantation 1989; 47: $828-834$.

62 Keogh AM, Howlett TA, Perry L, Rees LH. Pituitary function in brain-stem dead organ donors: a prospective survey. Transplant Proc 1988; 20: 729 - 730 . 
63 Powner DJ et al. Hormonal changes in brain dead patients. Crit Care Med 1990; 18: $702-708$.

64 Boelen A et al. Induced illness in interleukin-6 (IL-6) knock-out mice: a causal role of IL-6 in the development of the low 3,5,3'triiodothyronine syndrome. Endocrinology 1996; 137: 52505254.

65 Hashimoto $\mathrm{H}$ et al. The relationship between serum levels of interleukin-6 and thyroid hormone in children with acute respiratory infection. J Clin Endocrinol Metab 1994; 78: 288 - 291.

66 Berger MM, Lemarchand-Béraud T, Cavadini C, Chioléro R. Relations between the selenium status and the low $\mathrm{T} 3$ syndrome after major trauma. Intensive Care Med 1996; 22: 575 - 581

67 Karayalçin $\mathrm{K}$ et al. Donor thyroid function does not affect outcome in orthotopic liver transplantation. Transplantation 1994; 57: $669-672$.

68 Novitzky D, Cooper DK, Morrell D, Isaacs S. Change from aerobic to anaerobic metabolism after brain death, and reversal following triiodothyronine therapy. Transplantation 1988; 45: $32-36$.

69 Washida $\mathrm{M}$ et al. Beneficial effect of combined 3,5,3'triiodothyronine and vasopressin administration on hepatic energy status and systemic hemodynamics after brain death. Transplantation 1992; 54: $44-49$.

70 Clark RE. Cardiopulmonary bypass and thyroid hormone metabolism. Ann Thorac Surg 1993; 56(suppl 1): S35-S41/ discussion $\mathrm{S} 41-\mathrm{S} 42$

71 Klemperer JD, Klein I, Gomez $\mathrm{M}$ et al. Thyroid hormone treatment after coronary-artery bypass surgery. $N$ Engl $\mathrm{J}$ Med 1995; 333: $1522-1527$.

72 Hsu R-B, Huang T-S, Chen Y-S, Chu S-H. Effect of triiodothyronine administration in experimental myocardial injury. J Endocrinol Invest 1995; 18: $702-709$.

73 Sypniewski E. Comparative pharmacology of the thyroid hormones. Ann Thorac Surg 1993; 56(suppl 1): S2-S6/ discussion $\mathrm{S} 6-\mathrm{S} 8$.

74 Utiger RD. Altered thyroid function in nonthyroidal illness and surgery. N Engl J Med 1995; 333: $1562-1563$.

75 Goarin J-P et al. The effects of triiodothyronine on hemodynamic status and cardiac function in potential heart donors. Anesth Analg 1996; 83: $41-47$

76 Randell TT, Höckerstedt KAV. Triiodothyronine treatment in brain-dead multiorgan donors - a controlled study. Transplantation 1992; 54: $736-738$.

77 Chopra IJ. Clinical review 86: Euthyroid sick syndrome: Is it a misnomer? J Clin Endocrinol Metab 1997; 82: 329 - 334

78 Rolih CA, Ober KP. The endocrine response to critical illness. Med Clin North Am 1995; 79: 211 - 224

79 Cheville AL, Kirschblum SC. Thyroid hormone changes in chronic spinal cord injury. J Spinal Cord Med 1995; 18: 227 232

80 Mesard L, Carmody A, Mannarino E, Ruge D. Survival after spinal cord trauma. A life table analysis. Arch Neurol 1978; 35: $78-83$.

81 Carter RE, Graves DE. Spinal cord injury occurring in older individuals. In: Narayan RK, Wilberger Jr JE, Povlishock JT (eds). Neurotrauma. McGraw-Hill: New York 1996; pp $1281-$ 1287.

82 Piepmeier JM. Late sequelae of spinal cord injury. In: Narayan RK, Wilberger Jr JE, Povlishock JT (eds). Neurotrauma McGraw-Hill: New York 1996, pp 1237 - 1244
83 Fitzgerald RD et al. Cardiovascular and catecholamine response to surgery in brain-dead organ donors. Anaesthesia 1995; 50: $388-392$

84 Fitzgerald RD et al. Endocrine stress reaction to surgery in brain-dead organ donors. Transpl Int 1996; 9: $102-108$.

$85 \mathrm{Gramm} \mathrm{H}-\mathrm{J}$ et al. Hemodynamic responses to noxious stimuli in brain-dead organ donors. Intensive Care Med 1992; 18: 493 495.

86 Gramm H-J, Schäfer M, Link J, Zimmermann J. Authors' reply and report on another manifestation of a possible rise in sympathoadrenal activity during retrieval surgery. Intensive Care Med 1994; 20: 165-166.

87 Hill DJ, Munglani R, Sapsford D. Haemodynamic responses to surgery in brain-dead organ donors [letter; comment]. Anaesthesia 1994; 49: $835-836$.

88 Pennefather SH, Dark JH, Bullock RE. Haemodynamic responses to surgery in brain-dead organ donors. Anaesthesia 1993; 48: $1034-1038$.

89 Pennefather SH. Hemodynamic responses to noxious stimuli in brain-dead organ donors [letter; comment]. Intensive Care Med 1994; 20: 165

90 Fiser DH, Jimenez JF, Wrape V, Woody R. Diabetes insipidus in children with brain death. Crit Care Med 1987; 15: 551- 553.

91 García OD et al. Heart rate variability in coma and brain death. In: Machado C (ed). Brain Death. Proceedings of the Second International Conference on Brain Death. Havana, Cuba, February 27-March 1, 1996. Elsevier: Amsterdam 1995, pp $191-197$

92 Goldstein B et al. Autonomic control of heart rate after brain injury in children. Crit Care Med 1996; 24: 234-240.

93 Blaustein AS, Walsh RA. Regulation of the cardiovascular system. In: Sperelakis N, Banks RO (eds). Essentials of Physiology. 2nd edn. Little, Brown and Company: Boston 1996; pp 309-321.

94 Kopp UC, DiBona GF. Neural control of volume homeostasis. In: Brenner BM, Stein JH (eds). Body Fluid Homeostasis. Churchill Livingstone: New York 1987, p 185-220.

95 Moss NG, Colindres RE, Gottschalk CW. Neural control of renal function. In: Windhager EE (ed). Handbook of Physiology. A critical, comprehensive presentation of physiological knowledge and concepts. Section 8: Renal Physiology. Oxford University Press: New York 1992; pp 1061-1128.

96 Shewmon DA. The brain and somatic integration: insights into the standard biological rationale for equating 'brain death' with death. J Med Philos 1999; [in press].

97 Litvinoff JS. Maternal brain death during pregnancy [letter]. JAMA 1989; 261: 1729 .

98 Task Force for the Determination of Brain Death in Children. Guidelines for the determination of brain death in children. Ann Neurol 1987; 21: 616-617.

99 Black PMcL. Brain death (Second of two parts). $N$ Engl J Med 1978; 299: $393-401$

100 Halevy A, Brody B. Brain death: reconciling definitions, criteria, and tests. Ann Intern Med 1993; 119: 519-525.

101 Taylor RM. Reexamining the definition and criteria of death. Semin Neurol 1997; 17: 265-270.

102 Truog RD. Is it time to abandon brain death? Hastings Cent Rep 1997; 27(1): 29-37. 